\section{Drought Stress Can Produce Small but not Compact Marigolds}

\author{
Marc W. van Iersel ${ }^{1}$ and Krishna S. Nemali \\ Department of Horticulture, University of Georgia, 1111 Miller Plant Science \\ Building, Athens, GA 30602-7273 \\ Additional index words. bedding plants, capillary mat, irrigation, height control, \\ subirrigation, Tagetes erecta $\mathrm{L}$.
}

\begin{abstract}
We examined the effectiveness of an elevated capillary mat system to maintain constant and different moisture levels in the growing medium and verify the potential of drought stress conditioning in producing small and compact bedding plants. To differentiate between plant height and compactness, we determined compactness as the leaf area or dry mass per unit stem length. Marigold 'Queen Sophia' (Tagetes erecta $\mathrm{L}$.) seedlings were grown in square, $9-\mathrm{cm}$-wide, $10-\mathrm{cm}$-high containers filled with a soilless growing medium. A capillary mat was laid on top of a greenhouse bench which was raised by $15 \mathrm{~cm}$ on one side compared to the other side to create an elevation effect. Seedlings were subirrigated by immersing the low end of the capillary mat in a reservoir of water. The amount of water moving to the higher end of the mat progressively decreased with elevation. The moisture content in the growing medium averaged from 26 to $294 \mathrm{~mL} / \mathrm{pot}$ at different elevations. Regression analysis indicated that growth parameters including, shoot dry mass, leaf area, leaf number, and plant height decreased linearly with decreasing soil moisture content in the growing medium. Of all the measured growth parameters, plant height was found to be least sensitive to decreasing moisture content in the growing medium. Plants in high moisture treatments had more dry mass and leaf area per unit length of the stem compared to those in low moisture treatments. Our results indicate that drought stress can produce small, but not truly compact bedding plants.
\end{abstract}

Excessive elongation of bedding plants during greenhouse production is common and results in low-quality plants. Excessively tall plants generally are considered to be of low quality due to the increased shipping costs of these plants and their increased susceptibility to lodging. One method to limit elongation is to limit water uptake by plants. Drought stress conditioning involves exposing plants to nonlethal water deficits (Latimer and Severson, 1997). Imposing drought stress not only controls plant growth, but also conditions plants for stresses during shipping, marketing, and after planting in the landscape (Latimer and Oetting, 1998). Drought stress is commonly used to condition bedding plants in greenhouse production (Brown et al., 1992; Latimer, 1992; Latimer and Severson, 1997; Latimer and Oetting, 1998). Generally, drought stress is imposed by withholding water from the plants until they wilt or a targeted, low water potential of the growing medium is reached (Brown et al., 1992). With both methods, the time interval between subsequent irrigations may vary, because plant water use and evaporation from the growing medium depend on the environmental conditions (Brown et al., 1992). Therefore, plants are not subjected to identical drought stresses during subsequent wetting and drying cycles.

Drought stress conditioning can also be

Received for publication 19 Aug. 2003. Accepted for publication 13 Dec. 2003. We thank Keven Calhoun and Larry Freeman for their technical assistance, and George Elliott and an anonymous reviewer for their helpful comments on an earlier draft of this manuscript.

${ }^{1}$ To whom reprint requests should be addressed; e-mail address: mvanier@uga.edu. done by growing plants at a constant,but low, moisture content of the growing medium, although maintaining a constant moisture level may be difficult. By spreading a capillary mat, normally used for subirrigating greenhouse plants (Dole, 1994; Morvant et al., 2001), on a sloped surface and immersing the lower end of the mat in water reservoir, the amount of water in the capillary mat will progressively decrease with increasing elevation from the source of water. Thus, by growing plants on a sloped capillary mat, they can be exposed to different drought stresses, depending on the height of the pot above the level of water in the reservoir. Such a system can be used to determine how water supply affects plant growth and quality.

When plants are exposed to drought stress, stomates normally close to reduce water loss from the leaves (Chapman and Augé, 1994; Jones, 1998). Closure of stomates reduces transpiration, but at the cost of decreased photosynthesis (Jones, 1998). Compared to the decline in leaf photosynthesis, leaf expansion is more sensitive and ceases earlier in moisture-stressed plants (McCree, 1986). Although leaf expansion ceases, it is possible that stem elongation can continue at the same drought stress level. Due to lower resistance to water movement in the xylem tissue in stems compared to the water conducting veins in the leaves (Steudle, 2000), it is possible for stem cells to maintain a higher turgor pressure than leaf cells at a particular drought stress level. The higher turgor pressure may enable elongation of stem cells during periods of drought stress, although not necessarily at a rate seen in well-watered plants. Since stem cell elongation increases plant height, it is possible that height could be less sensitive to drought stress than leaf area development. Thus, regulating elongation by withholding water may result

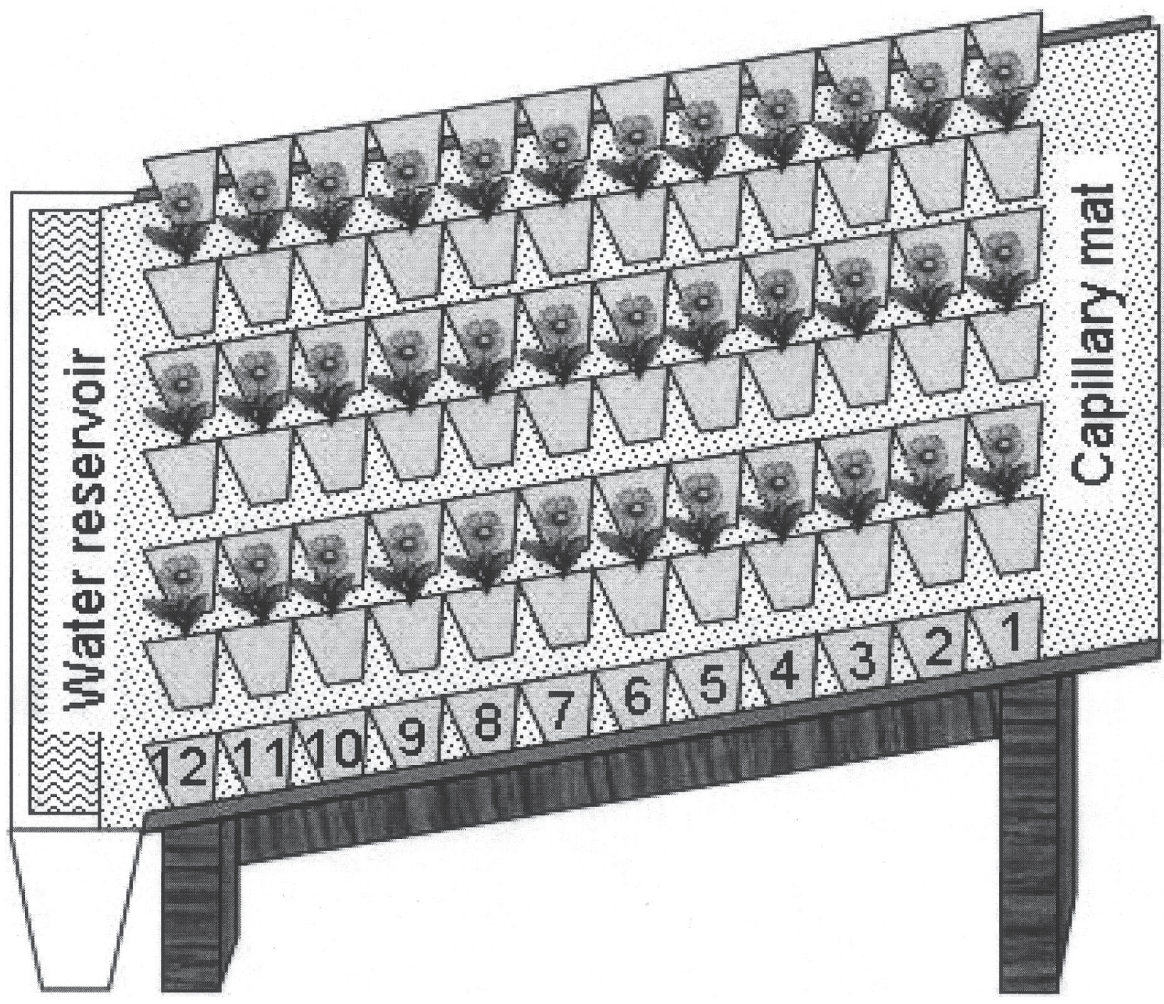

Fig. 1. Diagram of the experimental setup. Pots were arranged on a sloped capillary mat in 7 columns and 12 rows (indicated by the numbers on the pots). The highest pots were about $15 \mathrm{~cm}$ above the water level in the reservoir. 
in severe reductions in leaf area. In addition, drought may result in leaf abscission. In the drought-tolerant species Zizyphus rotundifolia Lam. for example, carbon is remobilized from leaves and preferentially distributed to stem and roots, while leaves are shed as water stress increases (Arndt, 2001).

Greenhouse growers normally use plant growth regulators to reduce seedling height (Brown et al., 1992; Latimer and Oetting, 1998). Relatively short bedding plants are preferred in the market due to their appearance, reduced shipping costs, and ease in handling during landscape planting. Since drought stress can reduce plant height, it can be an alternative to plant growth regulators. Although it is clear that drought stress can result in shorter seedlings (Latimer, 1992; Latimer and Severson, 1997), effects on other growth parameters such as leaf area, dry mass and flowering have not been studied in much detail. In most previous growth regulation research, compactness has been poorly defined and normally is considered to be the same as plant height. However, here we define compactness as an increase in leaf area or dry mass per unit plant height instead of just a reduction in height. For example, if drought reduces dry mass and/or leaf area more than stem elongation, it may result in smaller, but less compact plants. Therefore, the objectives of this research are to 1) study the effectiveness of a sloped capillary mat system to maintain constant, but different moisture levels in pots, 2) study the effects of drought stress on plant height and growth of marigolds, and 3) examine the potential of drought stress in producing compact marigolds.

\section{Materials and Methods}

Plant material and treatments. Marigold 'Queen Sophia' was seeded in plug trays (288 were transplanted into 9-cm-wide, 10-cm-high, square pots $(500 \mathrm{~mL})$ made out of compressed peat (\#240, Jiffy products, Batavia, Ill.). The pots were filled with a soilless growing medium (a mixture of sphagnum peat, perlite, vermiculite, and aged bark; Fafard 4P, Fafard, Anderson, S.C.) and $13 \mathrm{~g}$ of a $14 \mathrm{~N}-6.2 \mathrm{P}-12 \mathrm{~K}$ slow release fertilizer (Osmocote 14-14-14, The Scotts Co., Marysville, Ohio) was incorporated into the growing medium in each pot before transplanting. In total, 84 pots were filled with the growing medium, but only 36 pots were transplanted with seedlings.

The irrigation system was based on the approach of Buxton and Jia (1999), who showed that the moisture content in a capillary mat, and thus in the pots on that mat, depends on the height of the mat above the water level in the water reservoir. Both transplanted and non-transplanted pots were placed on a capillary mat (Vattex F; OS Plastics, Norcross, Ga.) $(1.8 \times 1.8 \mathrm{~m})$ spread over a rigid plastic sheet on top of a greenhouse bench (Fig. 1). To improve the capillary contact between the pots and the capillary mat, the perforated plastic which normally covers the capillary mat was not used. Prior to placing the capillary mat on the bench, it was treated with wetting agent cells/flat). At $11 \mathrm{~d}$ after seeding, seedlings
(Suffusion, Olympic horticultural products, Bradenton, Fla.) to facilitate absorption of water. About $30 \mathrm{~cm}$ of the mat extended down one side of the bench, and this section of the mat was placed in a water reservoir attached to the side of the bench. The water level in this reservoir was maintained at a steady level. The bench side opposite from the water reservoir was raised by about $15 \mathrm{~cm}\left(\approx 7^{\circ}\right.$ angle $)$ to place the capillary mat at a slope.

The 84 pots were placed in a grid of 12 rows and 7 columns, with the rows parallel and the columns perpendicular to the water reservoir at the base of the mat. Thus, the pots within a column were at different elevations above the water reservoir, resulting in differences in the moisture content of the growing medium in those pots, while pots within a row were at the same elevation. The sides of the pots within each column touched each other, while different columns were spaced by about $10 \mathrm{~cm}$. Every alternate column contained transplanted pots (columns 2, 4, and 6), while the remaining columns $(1,3,5$, and 7$)$ each contained twelve non-transplanted pots.

Measurements. All the pots were weighed at weekly intervals. At the end of the experiment, pots were dried in a forced-air oven for a week at $80^{\circ} \mathrm{C}$. The dry mass of the pots was subtracted from the fresh mass of the pots throughout the experiment to determine the moisture content in the pots without plants. We assumed that within a row, the moisture content was similar in pots with and without plants. However, it is possible that plant water use reduced the water content in the pots with plants, as compared to those pots where water loss was by evaporation only.

At the end of the experiment (5 weeks after transplanting, when plants flowered), plant height, number of leaves, leaf area and shoot dry mass of each plant were measured. To assess the compactness of the plants, the ratios of shoot dry mass and leaf area to plant height were calculated, with a higher value indicating a more compact plant (i.e., more dry mass or leaf area per unit height).

Statistical design and analysis. Since all

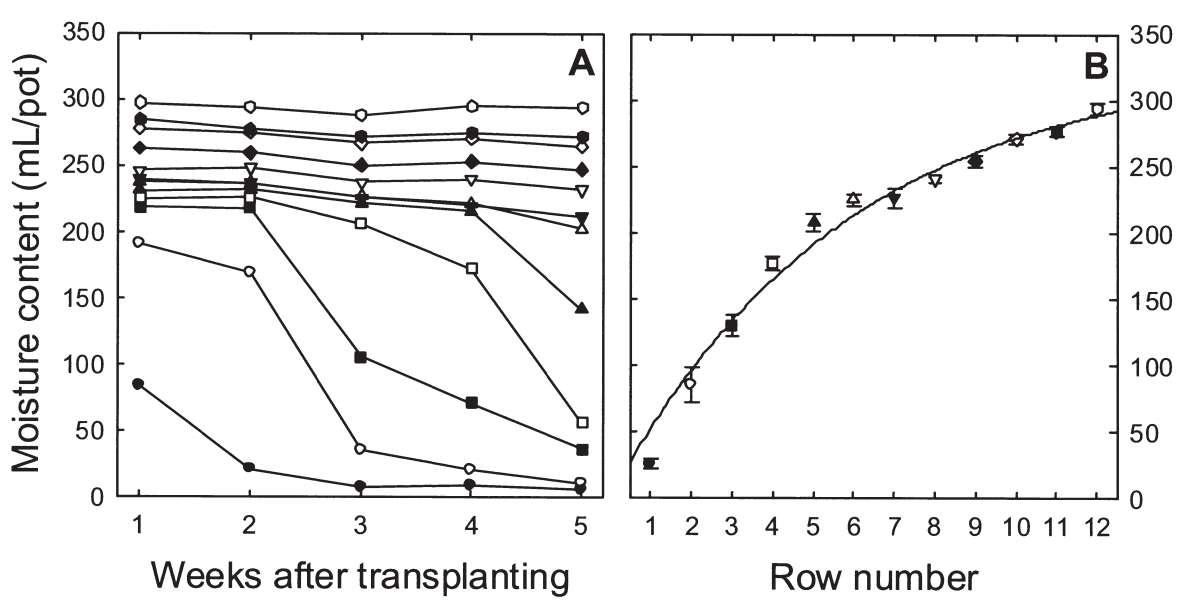

Fig. 2. Moisture content in the growing medium at different times during the experiment (A) and mean moisture content $( \pm \mathrm{SE}, \mathrm{n}=4$ ) over the duration of the experiment $(\mathbf{B})$. Data were collected from pots without plants. Symbols indicate different rows or treatments and are arranged in an ascending order [row 1 (driest) to 12 (wettest)] from bottom to top $(\mathbf{A})$. Average moisture content $=330 \times\left(1-\mathrm{e}^{-0.174}\right.$ $\times$ row number $), R^{2}=0.96$.

treatments were arranged on the same sloped capillary mat, true replications were not used. Instead, there were three pseudo-replications for plant growth measurements and four pseudo-replications for growing-medium moisture measurements. In addition, due to the method of applying different substrate moisture levels (height above and distance from the water reservoir), randomization of the treatments was not possible. The lack of true replications had little effect on data analysis, since linear and non-linear regression analyses (statistical analysis software, SAS institute, N.C.) were used, with $P<0.05$ considered to be statistically significant. Regression analysis, unlike analysis of variance, is not dependent on replications.

Since the plants closest to the water reservoir only had neighboring plants on one side, they received more light than the rest of the plants, which resulted in faster growth. Therefore, they were not included in the analyses. Plants in the two driest treatments died before the end of the experiment. Plants in the driest treatment with surviving plants also had neighboring plants on only one side. In this treatment however, growth clearly was limited more by water availability than by light, so the results from those plants are included in the analyses. Therefore, plotted plant data contained results from nine moisture treatments. Because the moisture content in the growing medium was not constant throughout the experiment, the average moisture content was used in regression analyses of moisture content versus plant growth parameters.

\section{Results and Discussion}

Moisture content in the growing medium. At any time, the moisture content of the growing medium was greatly affected by the distance from the water reservoir (Fig. 2). The sloped capillary mat was only able to maintain a constant moisture level in the growing medium at low elevations (i.e., rows 6 through 12). Since pots were watered thoroughly after transplanting, the growing medium subsequently dried
HortScience Vol. 39(6) October 2004 


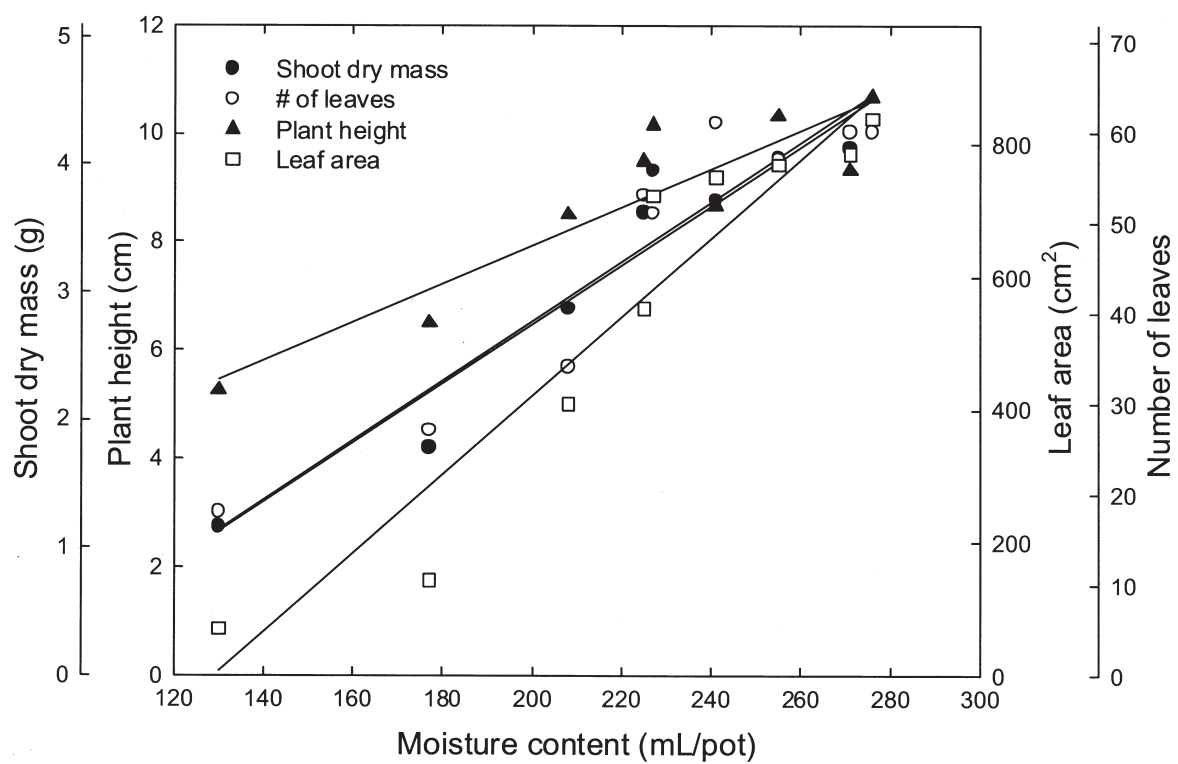

Fig. 3. Effect of different moisture levels in the growing medium on shoot dry mass, leaf area, leaf number, and plant height of marigolds at the end of the experiment. Data points are the average of three replications. Shoot dry mass $=-1.91+0.0232 \times$ moisture content $\left(r^{2}=0.71\right)$, plant height $=0.97+0.035 \times$ moisture content $\left(r^{2}=0.63\right)$, leaf number $=-27.0+0.33 \times$ moisture content $\left(r^{2}=0.57\right)$, and leaf area $=-762+5.92 \times$ moisture content $\left(r^{2}=0.73\right), P<0.001$ for all regressions
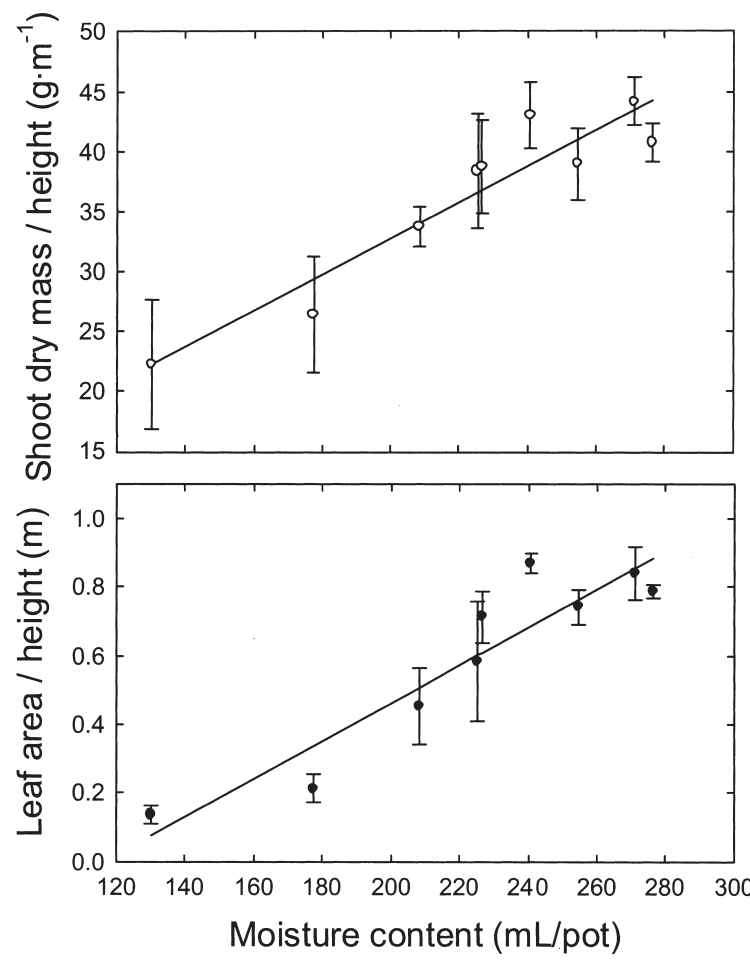

(row 1) (Fig. 2B). The average moisture content throughout the experiment ranged from 26 (row 1) to $294 \mathrm{~mL} /$ pot (row 12) (or a volumetric water content of about $5 \%$ to $59 \%$ ). The relationship between the moisture content in the growing medium and elevation was non-linear. Differences in the moisture content of the growing medium in adjacent rows increased with increasing elevation (or distance form the water reservoir). This may be due to the non-linear relationship between substrate volumetric moisture content and matric potential (Karlovich and Fonteno, 1986) and/or evaporative water losses from the capillary mat. Pots in rows 1 and 2 dried out almost completely, resulting in the death of these plants.

Growth measurements. Plant growth, including shoot dry mass, leaf area, leaf number, and plant height, decreased linearly with decreasing moisture content in

Fig. 4. Effect of different moisture levels in the growing medium on the ratio of shoot dry mass to plant height and leaf area to plant height of marigolds at the end of the experiment. Data are the average of three replications $( \pm \mathrm{SE})$. Shoot dry mass $/$ plant height $=0.026+0.0015 \times$ moisture content $\left(r^{2}=0.58\right)$, leaf area/plant height $=-0.65$ $+0.0055 \times$ moisture content $\left(r^{2}=0.69\right), P<$ 0.001 for all regressions.

out gradually, in particular in pots at higher elevations. Averaged over the duration of the experiment, the moisture content in the growing medium was highest in the pots closest to the water reservoir (row 12) and lowest in the pots at the highest elevation pressure result in smaller leaf areas for plants grown under drought stress as compared to well-watered plants. A decrease in leaf area and subsequent decline in photosynthesis due to closure of stomates results in overall decrease in growth of plants. Reduction in plant height due to drought stress has been reported earlier for tomato (Lycopersicon esculentum Mill.), marigold (Tagetes erecta L.) (Brown et al., 1992), New Guinea impatiens (Impatiens $\times$ hybrida L.) (Latimer and Oetting, 1998), and broccoli (Brassica oleracea L.) (Latimer and Severson, 1997). However, an important difference between those studies and our work is that in the previous studies, substrate moisture level fluctuated. The growing medium dried out between irrigations, but was replenished at each irrigation, thus resulting in episodic drought. In the current study, the substrate moisture content in the drier treatments declined gradually throughout the experiment. Such a gradual imposition of drought stress may affect plants differently from episodic drought.

Plant height was less sensitive to decreasing moisture content in the growing medium than leaf area, shoot dry mass, or the number of leaves (Fig. 3). Relative to the plants grown at the highest moisture level, plant height at the lowest moisture level decreased by $51 \%$ compared to $70 \%, 73 \%$, and $92 \%$ for number of leaves, shoot dry mass, and leaf area, respectively. Osório et al. (1998) reported that leaf expansion of eucalyptus (Eucalyptus globulus Labill.) seedlings under severe drought conditions was 1.5 to 2.0 times greater for leaves on the main stem axis compared to those on branches. Apparently, under drought stress conditions, higher growth rates may be seen in stem and parts closely associated with stem compared to those parts further away from the stem (e.g., leaves on branches). Results from Osório et al. (1998) and our experiment indicate that stem elongation, and therefore plant height, are less sensitive to drought stress than leaf expansion.

Compactness in plants. Drought stress did not result in compact plants. Shoot dry mass per unit plant height increased linearly with increasing moisture content in the growing medium (Fig. 4). This indicates that the plants grown at the lowest moisture level weighed less per unit stem length than those grown at the highest moisture level. Similar to shoot dry mass per unit plant height, leaf area per unit plant height also decreased linearly with decreasing moisture content in the growing medium (Fig. 4). Our results indicate drought stress results in shorter, but not more compact, plants. Although regression analysis suggested a linear relationship between moisture content and plant growth and compactness (Figs. 3 and 4), it is interesting to note that treatment effects were negligible in the range of moisture contents from 240 to $280 \mathrm{~mL} / \operatorname{pot}(48 \%$ to $56 \%$ ). This likely is related to the hydraulic properties of peat-based substrates. A large fraction of the water in peat-based media is held at a water potential between 0 and $-5 \mathrm{kPa}$ and this water is readily available to plants (Karlovich and Fonteno, 1986). Therefore, small changes in the volumetric water content of moist media 
are unlikely to have much effect on water availability and plant growth.

\section{Conclusions}

The sloped capillary mat system was able to produce different moisture levels in the growing medium, but moisture levels in the drier treatments were not constant during the experiment. Although drought stress can produce small plants, plant height was less sensitive to drought stress than leaf area, number of leaves, or dry mass. Thus, the measures of compactness (dry mass or leaf area per unit plant height) indicated that plants grown at high moisture content were more compact, but also taller. Although drought stress can be used to reduce growth and produce small bedding plants, drought-stressed plants may not be truly compact if grown with a gradually declining low moisture level. However, under production conditions the moisture level of the growing medium fluctuates, since the growing medium is generally resaturated at each irrigation. If the growing medium dries out between irrigations, this results in periodic drought stress, which may affect plants differently from gradually decreasing moisture levels. The effect of such episodic drought stress on compactness warrants further investigation.

\section{Literature Cited}

Arndt, S.K. 2001. Physiological and morphological adaptations of the fruit tree Zizyphus rotundifolia in response to progressive drought stress. Tree Physiol. 21:705-715.

Brown, R.D., J. Eakes, B.K. Behe, and C.H. Gilliam. 1992. Moisture stress: An alternative method of height control to B-nine (daminozide). J. Environ. Hort. 10:232-235.

Buxton, J.W. and W. Jia. 1999. A controlled water table irrigation system for hydroponic lettuce production. In: A.P. Papadopoulos (ed.). Proceedings of the international symposium on growing media and hydroponics. Acta Hort. 481:281-287.

Chapman, D.S. and R.M. Augé. 1994. Physiological mechanisms of drought resistance in four native ornamental perennials. J. Amer. Soc. Hort. Sci. 119:299-306.

Dole, J.M. 1994. Growth of poinsettias, nutrient leaching, and water-use efficiency respond to irrigation methods. HortScience 29:858-864.

Frensch, J. 1997. Primary responses of root and leaf elongation to water deficits in the atmosphere and soil solution. J. Expt. Bot. 48:985-999.

Hsiao, T.C. and L.K. Xu. 2000. Sensitivity of growth of roots versus leaves to water stress: biophysical analysis and relation to water transport. J. Expt. Bot. 51:1595-1616.

Jones, H.G. 1998. Stomatal control of photosynthesis and transpiration. J. Expt. Bot. 49:387-398.

Karlovich, P.T. and W.C. Fonteno. 1986. Effect of soil moisture tension and soil water content on the growth of chrysanthemum in 3 container media. J. Amer. Soc. Hort. Sci. 111:191-195.

Latimer, J.G. 1992. Drought, paclobutrazol, abscisic acid, and gibberellic acid as alternatives to daminozide in tomato transplant production. J. Amer. Soc. Hort. Sci. 117:243-247.

Latimer, J.G. and R.F. Severson. 1997. Effect of mechanical and moisture-stress conditioning on growth and cuticle composition of broccoli transplants. J. Amer. Soc. Hort. Sci. 122:788-791.

Latimer, J.G. and R. Oetting. 1998. Greenhouse conditioning affects landscape performance of bedding plants. J. Environ. Hort. 16:138-142.

Lockhart, J.A. 1965. Cell extension, p. 826-849. In: J. Bonner and J.E. Varner (eds.). Plant biochemistry. Academic press, New York.

McCree. K.J. 1986. Whole plant carbon balance during osmotic adjustment to drought and salinity stress. Austral. J. Plant Physiol. 13:33-43.

Morvant, J.K., J.M. Dole, and J.C. Cole. 2001. Fertilizer source and irrigation system affect geranium growth and nitrogen retention. HortScience 36:1022-1026

Osório, J., M.L. Osório, M.M. Chaves, and J.S. Pereira. 1998. Water deficits are more important in delaying growth than in changing patterns of carbon allocation in Eucalyptus globulus. Tree Physiol. 18:363-373.

Steudle, E. 2000. Water uptake by roots: effects of water deficit. J. Expt. Bot. 51:1531-1542. 